\title{
"A gente quer comida, diversão e arte" - ação coletiva na cidade física e virtual ${ }^{1}$
}

\author{
"La gente quiere comida, diversión y arte" - acción colectiva en la ciudad \\ física y virtual
}

"We want food, fun and art" - collective action in physical and virtual city

\author{
Kary Emanuelle Reis Coimbra ${ }^{2}$
}

\begin{abstract}
Resumo
Este trabalho é fruto de um estudo bibliográfico na busca de reflexões acerca de experiências e possibilidades da ação coletiva dos sujeitos a partir de matrizes culturais, artísticas e/ou estéticas, seja no ambiente concreto e físico dos espaços públicos urbanos, seja via mídias e redes sociais digitais. Nesta busca, embasamo-nos nas teorias sobre cidade e a produção do espaço, assim como seus usos e contra-usos na construção democrática; e em teorias com evidência na perspectiva cultural da ação política. Nessa conjuntura, expressões culturais e artísticas representam não meros instrumentos cuja ação política se materializa para a busca de transformações sociais, mas são, elas próprias, a razão e a energia vital da ação. Ademais, o surgimento do ambiente virtual expandiu a esfera da comunicação, da expressão de diferenças, identidades e reivindicações, que, por um lado favoreceu a ampliação da participação dos sujeitos, e, ao mesmo tempo, tornou mais complexa a análise da ação coletiva nas cidades.
\end{abstract}

Palavras-chave: ação coletiva; direito à cidade; manifestações culturais.

\section{Resumen}

Este trabajo es fruto de un estudio bibliográfico en la búsqueda de reflexiones acerca de experiencias y posibilidades de la acción colectiva de los sujetos a partir de matrices culturales, artísticas y / o estéticas, sea en el ambiente concreto y físico de los espacios públicos urbanos, sea vía medios y redes sociales digitales. En esta búsqueda, en teorías sobre la ciudad y la producción del espacio, así como sus usos y contra-usos en la construcción democrática; y en teorías con evidencia en la perspectiva cultural de la acción política. En esa coyuntura, tales expresiones representan no meros instrumentos cuya acción política se materializa para la búsqueda de transformaciones sociales, pero son ellas mismas la razón y la energía vital de la acción. Además, el surgimiento del ambiente virtual expandió la esfera de la comunicación, de la expresión de diferencias, identidades y reivindicaciones, que, por un lado, favoreció la ampliación de la participación de los sujetos, y al mismo tiempo hizo más compleja el análisis de la acción colectiva en las ciudades.

Palabras claves: acción colectiva; derecho a la ciudad; manifestaciones culturales.

\begin{abstract}
This work is result of a bibliographical study in search for reflections about subjects's collective action's experiences and possibilities from cultural, artistic and / or aesthetic matrices, apparent in the concrete and physical environment of urban public spaces, or in social networks. In this search, in theories about city and the production of the space, as well as its uses and counter-uses in the democratic construction of society; and in theories with evidence in the cultural perspective of politicy action. At this
\end{abstract}

\footnotetext{
1 Artigo apresentado no Simpósio Temático (NOME DO SIMPÓSIO TEMÁTICO) durante o II Seminário Latino-Americano de Estudos em Cultura - SEMLACult em Foz do Iguaçu/PR, Brasil, 2018.

${ }^{2}$ Doutoranda em Políticas Públicas pela Universidade Federal do Piauí; Docente do Curso de Administração na Universidade Federal do Piauí; Teresina, Piauí, Brasil; karycoimbra@ufpi.edu.br
} 
juncture, these expressions don't represent mere instruments whose politicy action materializes for social transformations search, but are themselves the reason and the vital energy of action. Moreover, the emergence of the virtual environment has expanded the sphere of communication, the expression of differences, identities and demands, which favored the subjects participation's expansion and, at the same time, made more difficult the collective action analysis in the cities

Keywords: collective action; right to the city; cultural manifestations.

\section{Introdução}

O título que dá nome a este trabalho faz parte da música Comida, da banda brasileira Titãs. A música foi lançada no ano de 1984, no álbum 2 é Demais e, em 1987, no álbum Jesus Não Tem Dentes No País Dos Banguelas. O contexto brasileiro da época pairava sob ares de esperança da população acerca da (re)democratização e da recuperação das liberdades individuais. Numa aproximação à semântica da frase, ao exigir mais do que comida, querer também diversão e arte demonstra que, além de condições mínimas de sobrevivência, expressões individuais e de lazer são necessidades de todos, independentemente de condições econômicas e de classe. O caráter democrático da cultura foi expresso na Constituição Federal de 1988, que, além da concretização dos direitos de cidadania, trouxe e reconheceu também os direitos culturais como direitos fundamentais. Embora a Constituição garantisse tais direitos, na prática isto se deu também pela participação ativa da sociedade civil, tanto na reivindicação, quanto na realização de políticas e práticas culturais diversas.

A busca por mudanças - ora no quadro socioeconômico e político-institucional, ora no cultural - foi corporificada por clássicas manifestações e revoltas ao longo da história, onde os sujeitos, em coletivo, emanavam suas reivindicações frente aos governantes. Ao refletirem esses fenômenos, teóricos se debruçaram sobre os movimentos sociais e, entre suas diferentes vertentes, chegaram a problematizar possibilidades outras de ação coletiva, a exemplo da via cultural defendida na Teoria dos Novos Movimentos Sociais (ALONSO, 2009). A interrelação temática dos constructos cultura e política, entretanto, é característica não apenas dos ditos "novos" movimentos sociais, mas uma estrutura semelhante presente mesmo nos movimentos sociais tradicionais (ALVAREZ.; DAGNINO; ESCOBAR, 2000 - grifos dos autores). Isto porque, para Dagnino (1994), a transformação social e a construção de uma sociedade democrática perpassam pelas dimensões da política e da cultura, cujo papel das subjetividades e a insurgência de sujeitos sociais são características da sociedade contemporânea.

As práticas de intervenções urbanas ressignificam os espaços comuns em lugares de expressões de identidades, saberes, demandas e provocações sociais. A partir dos anos 2000, 
com o início da democratização do acesso à internet no Brasil e com o posterior surgimento das redes sociais, ativismos também passaram a ocorrer via mídia digital, possibilitando uma comunicação de amplo alcance e uma mobilização em escala jamais antes vista. Neste fluxo, termos como ciberespaço, cibercultura, ciberativismo e a ciberpolítica também foram problematizados no campo científico (LEVÝ, 1999). Isto posto, o objetivo norteador do estudo consistiu em refletir acerca de experiências e possibilidades da ação coletiva dos sujeitos a partir de matrizes culturais, artísticas e/ou estéticas, seja no ambiente concreto e físico dos espaços públicos urbanos, seja via mídias e redes sociais digitais. A partir de uma abordagem bibliográfica, objetivamos, pois, analisar ações coletivas insurgentes no âmbito da cidade sob a lente da cultura e da arte, analisando 1) experiências urbanas de manifestações por meio de apropriações e intervenções no espaço público, bem como 2) configurações contemporâneas de mobilização dos sujeitos através do ambiente virtual e das redes sociais.

\section{Manifestações culturais nas cidades: a ótica dos "novos" movimentos sociais}

A cidade não flui de maneira isolada; ela se transforma ao longo do tempo por meio das relações de sociabilidade nela desenvolvidas por "atores, relações sociais, personagens, grupos, classes, práticas de interação e de oposição, ritos e festas, comportamentos e hábitos. Marcas, todas, que registram uma ação social de domínio e transformação de um espaço natural no tempo" (PESAVENTO, 2007, p. 14). Objeto da produção de imagens e discursos que se colocam no lugar da materialidade e do social e os representam, a cidade também é um fenômeno que brota de emoções e sentimentos pelo viver urbano, pela expressão de utopias, de esperanças, de desejos e medos, individuais e coletivos que esse habitar proporciona. As cidades são, assim, visíveis, sensíveis e imaginárias.

No Brasil, a ação de sujeitos e coletivos na cidade passou por reivindicações tanto no âmbito socioeconômico, quanto no cultural. Sobre este último, manifestações de viés artístico aconteceram de maneira representativa na época do regime militar. Souza (2015), em uma análise da "arte sobre a ditadura militar", destaca que a esfera institucional brasileira neste período esteve concentrada em uma política cultural estratégica. Embora neste período tenha sido criado o Conselho Federal de Cultura (CFC) em 1966 e, mais tarde, a criação da Fundação Nacional de Arte (FUNARTE), em 1975, os esforços institucionais estavam voltados para a censura e repressão a produções artísticas diversas da época. Assim, tanto artistas quanto grupos e movimentos coletivos utilizaram-se da arte enquanto veículo político, no intuito da criação de uma estética que influenciasse a sociedade, visto que os "cruzamentos entre ativismo artístico e ativismo político podem ser notados, uma vez que as estratégias por 
eles usadas se avizinham bastante, muitas vezes, privilegiando a mensagem em detrimento do artístico" SOUZA (2015, p. 4).

Em 1961, no Rio de Janeiro, surgiu o Centro Popular de Cultura (CPC), uma organização vinculada à União Nacional dos Estudantes (UNE), que integrava artistas do teatro, da música, do cinema, da literatura e das artes plásticas com objetivo de criar e divulgar uma "arte popular revolucionária" em defesa do "caráter coletivo e didático da obra de arte e o engajamento político do artista" - revelando a incorporação da concepção de arte como função social. A expressão da contracultura na música, na literatura e nas artes plásticas ganhou força no Tropicalismo, movimento que se valia da experiencia estética como instrumento social revolucionário e teve como expoentes o artista plástico Hélio Oiticica; músicos do álbum Tropicalia ou Panis et Circencis, como Chico Buarque, Caetano Veloso e o poeta piauiense Torquato Neto. O movimento foi repreendido em um espetáculo cuja bandeira com os dizeres "Seja Marginal, Seja Herói”, de Oiticica, foi pendurada junto à imagem do traficante Cara-de-Cavalo, assassinado pela política (SOUZA, 2015, p.5).

A música brasileira desta época foi fortemente politizada e até hoje são conhecidas como símbolo de resistência. Na moda, a estilista Zuzu Angel protagonizou com ineditismo um desfile de caráter político, com a coleção Helpless Angel. Nas artes visuais, cineastas como Paulo César Saraceni e Joaquim Pedro de Andrade, que retrataram aspectos específicos do regime militar, e Glauber Rocha, com o filme Terra em Transe, apresentando a mudança revolucionária própria forma estética. (SOUZA, 2015; STIGGER; GERBASE, 2012).

Mesmo após a (re)democratização brasileira e a recuperação das liberdades individuais de expressão, grupos e manifestações artísticas continuaram incorporando um viés político em suas obras, agora problematizador não apenas da esfera institucional e dos órgãos e formas de governo, mas também - e principalmente - com questões pontuais relacionadas à cultura e aos modos de viver e se reconhecer na sociedade.

Alvarez, Dagnino e Escobar (2000, p. 23) apontam que, na América Latina, embora os "novos" movimentos fossem aqueles relacionados a "novas formas de fazer política" a partir de novas sociabilidades, a convencionalidade da necessidade de recursos, característica dos movimentos urbanos, operários e camponeses, por exemplo, também carregavam em si forças culturais. Isto é, "as identidades e estratégias coletivas de todos os movimentos sociais estão inevitavelmente vinculadas à cultura." Ou, nas palavras de Touraine (1994, p. 254). "um 
movimento social é, ao mesmo tempo, um conflito social e um projeto cultural (...) nada deve separar valores culturais e conflito social".

Gohn (1997; 2011) destaca os movimentos sociais como ações coletivas de base social, política e cultural para a expressão e organização das demandas dos indivíduos. Entre suas características clássicas, há um propósito pelo qual articulam sua ação na sociedade e, em função disso, nesses movimentos é possível visualizar a presença da identidade. Contribuem na organização e conscientização dos sujeitos e suas demandas são cobradas em forma de mobilizações e pressões sobre determinado grupo ou entidade social; nesse sentido, os movimentos também possuem um opositor, alguém ou algo sobre o que se discorda e se propõe mudanças. Para sua efetividade, é necessário ainda um grau de permanência e continuidade em suas ações (GOHN, 2011).

Predominante até a década de 1950, os movimentos sociais representavam a luta operária e os interesses de classes, protagonizado pelo operariado, seus sindicatos e associações, em busca da extensão de direitos que se pretendiam universais em nome do ideal de igualdade. Nas décadas de 1960 e 1970, no entanto, a emergência de novas características e atores sociais tornaram heteróclita a estrutura desses movimentos, que ganharam novas perspectivas teóricas e metodológicas e se popularizou com a nomenclatura de "novos movimentos sociais", numa dialética forma de anunciar permanências e mudanças. As reivindicações surgiam por grupos e atores específicos, como mulheres, negros, índios, homossexuais, deficientes; e o propósito se assentou em reivindicações específicas de direito contra formas outras de opressão que transcendiam a esfera estritamente econômica ou eminentemente política (GOLDMAN, 2007).

Nas palavras de Alonso (2009, p. 53), a Teoria dos Novos Movimentos Sociais floresceu a partir da "exaustão dos debates marxistas sobre as possibilidades da revolução", além da descrença em um sujeito histórico universal e em explicações deterministas e economicistas da ação coletiva, cujo elemento cultural - e não o econômico - norteava a ação dos movimentos sociais. Na "sociedade pós industrial" visualizada por Alain Touraine, a indústria e o trabalho perdem centralidade e a dominação passa a ser cultural, a partir do controle informacional e tecnocrático. A mudança, nesse sentido, "deveria ser" de ordem cultural, e o embate, não contra o Estado, mas a fim de conseguir sua anuência e reconhecimento.

Grupos de mulheres foram organizados nos anos 1990 em função de sua atuação na política, criando redes de conscientização de seus direitos e frentes de 
lutas contra as discriminações. O movimento dos homossexuais também ganhou impulso e as ruas, organizando passeatas, atos de protestos e grandes marchas anuais. Numa sociedade marcada pelo machismo, isso também é uma novidade histórica. O mesmo ocorreu com o movimento negro ou afrodescendente, que deixou de ser predominantemente movimento de manifestações culturais para ser, sobretudo, movimento de construção de identidade e luta contra a discriminação racial. Os jovens também criaram inúmeros movimentos culturais, especialmente na área da música, enfocando temas de protesto, pelo rap, hip hop etc. (GOHN, 2011, p. 343)

Gohn (2011) destaca a mudança discursiva sobre os ideais clássicos de igualdade, fraternidade e liberdade: a igualdade passa a ter caráter de busca por justiça social; a fraternidade soa elementos de solidariedade; e a liberdade relaciona-se com a autonomia quanto à inserção na sociedade e à inclusão social. Nesse sentido, esses "novos" movimentos seguem uma narrativa pautada na construção de uma sociedade democrática, por meio de novas culturas políticas de inclusão, identidades com base em questões como diferença e multiculturalismo.

A configuração das mobilizações e participação dos sujeitos no ambiente virtual é apontada como característica dos chamados novíssimos movimentos sociais. A internet, as mídias e redes sociais surgem como importantes instrumentos de organização, mobilização e comunicação para posteriores ocupações do espaço público urbano.

\section{Usos e contra-usos na cidade física e digital}

A cidade é um fenômeno de capilaridades específicas, densas e complexas. Constitui objeto de estudo multidisciplinar, apreciado por áreas como história, geografia, filosofia, sociologia, antropologia, urbanismo e administração, sem descartar outras ciências. A análise vai desde sua estrutura, distribuição, produção e reprodução, até constituição simbólica e representativa para os sujeitos que a habitam (ou não). Isto porque, embora abrigue a todos, é possível afirmarmos que a cidade é de todos, para todos? Ao problematizar o direito à cidade, Henri Lefebvre (2001) o apresenta como o direito à própria vida urbana, na cidade que se é obra - espaço de produção, criação e de apropriação.

Em A Revolução Urbana, Lefebvre (2008) narra a evolução do fenômeno urbano e sua relação de nascimento (e submissão) ao processo de revolução industrial. $\mathrm{O}$ autor aponta que o percurso inicial de uma sociedade organizada surgiu nos moldes da cidade política, estabelecida nas práticas da vida agrícola camponesa e em profundas relações de poder. No ocidente europeu, ao fim da Idade Média, o poder da mercadoria se instaura com o comércio em torno de uma praça central, onde logo em seguida se estruturam a Igreja e a Prefeitura. 
Assim a concepção de cidade e de urbano toma corpo como espaço de centralidades, "o lugar do encontro das coisas e das pessoas, da troca." O comércio torna-se função urbana, o que exige uma forma concreta que estruture o espaço urbano. Assim a cidade comercial vai sendo implantada dentro da cidade política e, até chegar ao modelo da cidade industrial (LEFEBVRE, 2008, p.20 - grifos do autor).

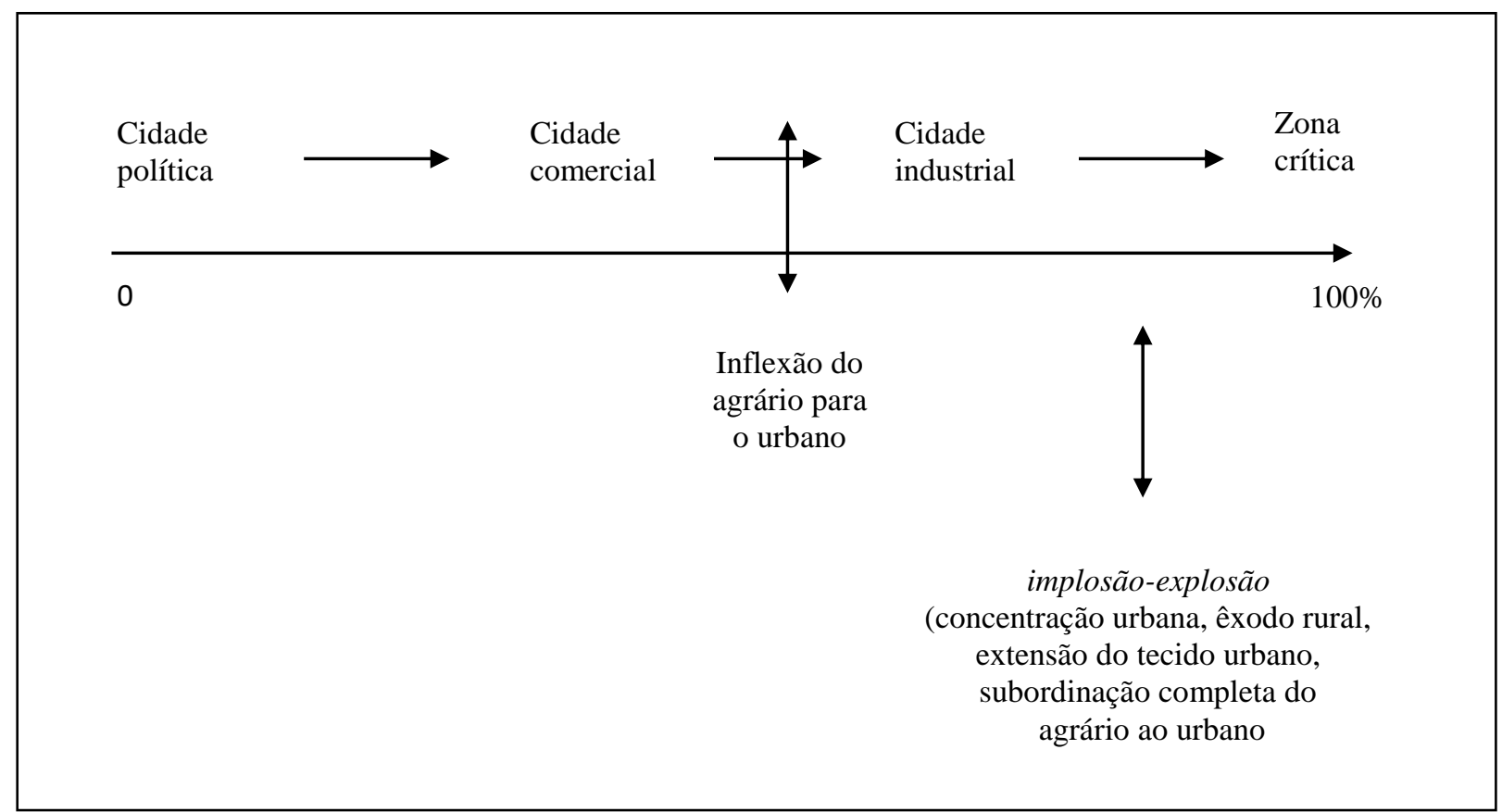

Figura 1 - O caminho percorrido pelo fenômeno urbano

Fonte: adaptado de Lefebvre (2008)

A cidade industrial "precede e anuncia" uma zona crítica: o urbano está em um ponto cego e a sociedade urbana ainda é um porvir. A realidade urbana atual encontra-se camuflada - em seu lugar atuam representações ideológico-institucionais comumente conhecidas como urbanismo. A zona crítica é, assim, uma espécie de caixa preta onde "sabe-se o que nela entra; às vezes percebe-se o que dela sai. Não se sabe bem o que nela se passa" (LEFEBVRE, 2008, p. 26). Esta fase crítica representa um campo cego, cegueira esta que se dá em função da redução do urbano à teoria e prática da industrialização, visto que "esse olhar redutor não permite vê-lo enquanto campo de tensões e conflitos, como lugar dos enfrentamentos e confrontações, unidade das contradições" (MARTINS, 2008).

Ao elencar o fenômeno da urbanização também podemos citar Foucault (2007), que analisa o surgimento medicina social e o processo de centralização de poder em cidades francesas no século XVIII. O autor destaca que a estrutura urbana francesa nesta época constituía-se de um emaranhado de microterritorios heterogêneos, o que dificultava o controle 
de sua dinâmica territorial. Desse modo, ainda na segunda metade do mesmo século, surgiu a necessidade de constituir a cidade como uma só unidade, organizada de modo coerente e homogêneo, sob a supervisão de um poder único, principalmente em função de razões econômicas e políticas.

Isso porque com a indústria nascente, a cidade tornou-se sinônimo de produção e de mercado e, nesse sentido, uma gestão centralizada facilitaria transações de ordem econômica. Ademais, se até século XVII a preocupação era com a eclosão de revoltas camponesas, no final do século XVIII, ao contrário, as revoltas urbanas tornam-se cada vez mais frequentes, o que possibilitou o desenvolvimento de um poder político forte e centralizado para seu controle (FOUCAULT, 2007).

No sentido mercadológico, turístico e consumista, "a cidade aparece como um bem material, consumida de acordo com as leis da reprodução do capital”. O espaço urbano é um meio de reprodução da mais-valia e possui um valor de troca; como produto, aparece na forma de mercadoria. Assim, o poder político do Estado tende a homogeneizar as práticas no espaço urbano por meio de seu controle (CARLOS, 1994, p. 85; CARLOS, 2006). Na ótica de Souza (2006), há que se perceber que o planejamento não consegue englobar todos os tipos de circunstâncias futuras, e nesse sentido, compreender a possibilidade das contingências, bem como a ocorrência de fatores adversos, não-planejáveis. O desafio do planejamento está, pois, na capacidade de planejar de modo não-racionalista e flexível e, nesse sentido, o processo de produção do espaço social se vê diante de um dualismo que envolve ambos planejamento e espontaneidade.

Os lugares, quando erguidos pelos contra-usos no interior dos processos de gentrification, podem representar formas táticas - especializadas e simbólicas - de criar singularidades, expressar dissensões e reivindicar direitos. Direitos de pertencer à cidade, de estabelecer itinerários próprios, de fazer do espaço público contemporâneo, enfim, um legítimo espaço político da diferença (LEITE, 2002, p.130).

Ana Fani Carlos (1994, p. 81) caracteriza a cidade como "o locus da concentração dos meios de produção e de concentração de pessoas; é o lugar da divisão econômica do trabalho". A cidade é também a concentração de população, instrumentos de produção, necessidades, atividades, serviços, infraestrutura, reserva de mão-de-obra e, ainda, mercadorias No entanto, "a cidade já não é mais vista como um mero cenário para a habitação e o trabalho, ou seja, como simples organização espacial, lugar de assentamento da indústria e dos serviços" (CANCLINI, 2002, p. 41), podendo servir também como espaço de resistência 
e de processos subjetivos. A participação de sujeitos e grupos sociais da sociedade civil se dá pelo uso do espaço público, de ruas, avenidas, calçadas e praças, territorializados por grupos com objetivos políticos, econômicos, religiosos ou culturais.

Mais que isso, a cidade agora é pensada e vivida para além de seus espaços físicos. Segundo Barbero (1998, p. 61), sob a perspectiva do paradigma informacional, a cidade também é virtual, um espaço comunicacional, numa "estreita simetria entre a expansão/fratura da cidade e o crescimento/adensamento dos meios e das redes eletrônicas." Isto é, estamos frente à "heterogeneidade de referentes identificatórios que propõe, à precariedade dos modos de enraizamento ou de pertencimento, à expansão estrutural do anonimato e às novas formas de comunicação que a própria cidade agora produz". A sociedade informacional ou sociedade em rede impulsiona a organização dos movimentos sociais

Há uma redefinição de esfera pública nesses movimentos, com parcerias com entidades de sociedade civil e política, além da construção de novos modelos de inovações sociais. A organização desses movimentos acontece no ambiente virtual, em redes sociais que chegam a ser desde locais até transnacionais (GOHH, 2011). A expansão da esfera pública para outras dimensões aconteceu em paralelo a um renascimento das energias políticas e de mobilizações que estavam adormecidas desde a época dos movimentos sociais para a (re)democratização brasileira. Em 2013, as Jornadas de Junho - como ficaram conhecidas as manifestações em caráter nacional que tiveram início com os protestos contra o aumento das passagens, idealizados pelo coletivo Movimento Passe Livre, deram visibilidade a esse novo formato de protagonismo juvenil, que era, concomitantemente, físico e digital. As mobilizações, organizadas pelas redes sociais por jovens da classe média com maior escolaridade, se materializavam em passeatas e protestos, movidas pelo bordão "o gigante acordou", uma metáfora ao despertar da politização e participação da sociedade civil no contexto político do país (SANTOS, 2015).

Pierre Levý (1999) relacionou a cidade com a democracia eletrônica e o ciberespaço, apontando a descentralização dos centros urbanos em novos formatos que proporcionariam desde a troca de saberes e experiencias, até maior participação política da população e redes de ajuda mútua e parcerias, demonstrando uma reforma nos modos de organização e hábitos políticos na sociedade, além do experimento de novas práticas democráticas.

\section{Algumas considerações}


Partindo de uma revisão bibliográfica de teorias sobre cidade, espaço público, ciberespaço e abordagens culturais da ação política coletiva, neste trabalho tivemos como objetivo de refletir acerca de experiências e possibilidades da ação coletiva dos sujeitos a partir de matrizes culturais, artísticas e/ou estéticas, seja no ambiente concreto e físico dos espaços públicos urbanos, seja via mídias e redes sociais digitais.

A análise de ações coletivas sob a lente econômica não foi suficiente para explicar especificidades do cotidiano das cidades, fazendo com que a cultura e a arte surgissem como pontos de reflexão. Embora tais grupos sociais se organizem em prol de modificações no cenário cultural, a dimensão política é um elemento intrínseco à sua atuação. Gohn (2011) destaca a importância dos movimentos sociais na modelagem da esfera pública, tendo em vista sua capacidade de construir modelos de inovações sociais e o estabelecimento de parcerias do escopo civil e político.

Evidência disso são nos registros históricos sobre a particip(ação) de artistas na luta contra o cerceamento das liberdades individuais durante o regime ditatorial brasileiro, em matrizes como a música, o cinema, as artes plásticas e a moda. A estética dos movimentos culturais artísticos que tiveram presença representativa na época explicitava, mutuamente, a expressão artística e a ação política dos sujeitos em seus produtos culturais. Nesse sentido, essas expressões não corporificaram a ação, mas já eram, elas próprias, a essência maior da ação. Em outras palavras, tais manifestações não funcionavam como o "corpo" da ação, e sim como sua "essência" - isto é, a essência da forma artística já era política.

Novos formatos de participação na cidade implicam novas formas de se pensar a própria cidade e suas teias de relações intersubjetivas. O planejamento urbano de políticas públicas, a integração Estado - sociedade civil e as pesquisas no campo científico cultural da urbe passam, agora, por novos desafios ao lidarem com fragmentações e novas centralidades. Se, anteriormente à popularização da internet, mobilizações populares centralizada em espaços públicos eram enfraquecidas e dispersadas em ações policiais e, por vezes, num simples despejar de gás lacrimogêneo, com a inserção das redes de comunicação digital, o ciberativismo e a tomada das redes sociais como campos de expressão sem "aparição" direta denotam a complexidade do fenômeno na contemporaneidade, aparentemente disperso e fragmentado.

Por outro lado, as redes sociais não eximiram a convocatória para ações presenciais na urbe. As Jornadas de Junho são um exemplo do poder das redes na mobilização para a centralidade, cujo alicerce está na formação e fortalecimento de grupos específicos e na veloz difusão de informações. A esfera pública se vê diante de novas faces, com novos movimentos 
e presenças físicas, ou mesmo sem face única, estilhaçada e distribuída virtualmente - a cidade lefebvriana que atrai e centraliza também é a cidade que explode e descentraliza.

\section{Referências}

ALONSO, A. As teorias dos movimentos sociais: um balanço do debate. Lua Nova, São Paulo, v. 76, p. 49-86, 2009.

ALVAREZ, S. E.; DAGNINO, E.; ESCOBAR, A. Introdução. O cultural e o político nos movimentos sociais latino-americanos. (Orgs.). Cultura e política nos movimentos sociais latino-americanos: novas leituras. Belo Horizonte: Editora UFMG, 2000, p. 15-57.

BARBERO, J. M. Cidade virtual: novos cenários da comunicação. Comunicação \& Educação, São Paulo, v. 11, p. 53-67, jan./abr., 1998.

BRITO, F. D.; JACQUES, P. B. Corpocidade: arte enquanto micro-resistência urbana. Fractal: Revista de Psicologia, Niterói, v. 21, n. 2, p. 337-350, mai/ago. 2009.

CANCLINI, N. G. Cidades e cidadãos imaginados pelos meios de comunicação. Opinião Pública, Campinas, v. 8, n. 1, p.40-53, 2002.

CARLOS, A. F. A. A (re)produção do espaço urbano. São Paulo: Edusp, 1994.

CARLOS, A. F. A. A natureza do espaço fragmentado. In: SANTOS, M.; SOUZA, M. A. A.; SILVEIRA, M. L. Território. Globalização e fragmentação. São Paulo: Hucitec, 2006.

CASTELLS, M. A sociedade em rede. São Paulo: Paz e Terra, 1999.

DAGNINO, E. Os movimentos sociais e a emergência de uma nova noção de cidadania. In: DAGNINO, E. (Org.) Anos 90. Política e sociedade no Brasil. São Paulo: Editora Brasiliense: 1994.

FOUCAULT, M. Microfísica do poder. 24. ed. Rio de Janeiro: Graal, 2007.

GOHN, M. G. Teoria dos movimentos sociais. Paradigmas clássicos e contemporâneos. São Paulo: Edições Loyola, 1997.

GOHN, M. G. Movimentos sociais na contemporaneidade. Revista Brasileira de Educação, v. 16, n. 47, maio-ago., 2011.

GOLDMAN, M. Introdução: políticas e subjetividades nos "novos movimentos culturais". Ilha - Revista de Antropologia. Florianópolis, v.9, n. 1, p. 8-22, jan - jul, 2007.

LEFEBVRE, H. O direito à cidade. São Paulo: Centauro, 2001.

LEFEBVRE, H. A revolução urbana. $3^{\text {a }}$ reimpressão. UFMG, 2008.

LEITE, R. P. Contra-usos e espaço público: notas sobre a construção social dos lugares na Manguetown. Revista Brasileira de Ciências Sociais, São Paulo, v. 17, n 49, p. 115-172 jun./2002. 
LEVÝ. P. Cibercultura. São Paulo: Editora 34, 1999.

MARTINS, S. Prefácio. In: LEFEBVRE, H. A revolução urbana. $3^{\text {a }}$ reimpressão. UFMG, 2008.

PESAVENTO, S. J. Cidades visíveis, cidades sensíveis, cidades imaginárias. Revista Brasileira de História, São Paulo, v. 27, n. 53, p. 11-23, jul. 2007.

SANTOS, V. V. V. Juventude e política: jornadas de junho e manifestações em Brasília. 2015. 47 f. Monografia (Graduação em Sociologia) - Universidade Federal de Brasília. Brasília. 2015.

SOUZA, M. L. Mudar a cidade: uma introdução à crítica ao planejamento e à gestão urbanos. 4. ed. Rio de Janeiro: Bertrand Brasil, 2006.

SOUZA, A. C. Cultura de memória no Brasil: arte sobre a ditadura militar. In: SEMINÁRIO DA PÓS-GRADUAÇÃO EM ARTES NA UFMG, 1, 2015, Belo Horizonte. Anais... Belo Horizonte: EBA UFMG, 2015. v. I.

STIGGER, H.; GERBASE, C. Cinema brasileiro e a experiência da ditadura militar. ALCEU, v. 13, n. 25, p. 110 a 122, jul./dez. 2012.

TOURAINE, A. Crítica da modernindade. Petrópolis: Vozes, 1994. 